\title{
Doenças tropicais: da ciência dos valores à valorização da ciência na determinação climática de patologias
}

\author{
Tropical diseases: from the science of values to praise \\ of science on the climatic determination of pathologies
}

Marli B. M. de Albuquerque 1

Francelina Helena Alvarenga Lima e Silva 2

Telma Abdalla de Oliveira Cardoso 2

\footnotetext{
${ }^{1}$ Casa de Oswaldo Cruz, Fundação Oswaldo Cruz, Av. Brasil 4036, sala 716, 21040-361, Manguinhos, Rio de Janeiro, RJ, Brasil. laura@fiocruz.br

2 Núcleo de Biossegurança, Fundação Oswaldo Cruz.
}

\begin{abstract}
Microbiology as we know, has given the theoretical and methodological elements to set up and evaluate the concept of "tropical disease", to confirm and establish it. Tropical Medicine is known today as a science dealing with parasites and infections, the most common causes of health affections throughout the intertropical zone of the globe. Due to a wider identification of these infections, this speciality has increased its scope, the infections having a natural diversity in the tropics. The vision of the tropics, which the main component included the climatic determination of disease, is decreased today by the concept that diseases are on a social and economic basis, as well as ecologically set up. This interpretation which highlights the physical and natural determinants of disease, tends to place climatic, geographic and biological factors on the same level, reducing man to the animal interaction plan and turning culture and society as another way of the environment.

Key words Tropical Diseases; Chagas Disease; Brazilian Medicine; History
\end{abstract}

Resumo A medicina e as observações científicas incorporam noções de valores culturais associados aos aspectos climáticos para definir um grupo nosológico específico denominado "doenças tropicais", "patologia dos climas quentes" ou ainda "doenças exóticas”. Pretendemos resgatar neste estudo a relevância do aspecto climático na definição de patologias, enfatizando as interseções ideológicas, políticas e culturais que contribuíram para a formulação de correntes de pensamento preocupadas em discutir cientificamente a importância do clima na construção ideológica de um "mundo particular", os trópicos.

Palavras-chave Doenças Tropicais; Doenças de Chagas; Medicina Brasileira; História 


\section{Os trópicos segundo os viajantes médicos e naturalistas a ciência dos valores; os trópicos como risco natural}

Desde o século XVIII, viajantes percorreram as terras do Brasil procurando estudar e classificar a natureza tropical, destacando os aspectos exóticos de um mundo tão vasto quanto diverso em paisagens e ares. No século XIX, a expansão das fronteiras das ciências físicas e biológicas seria decisiva para a formulação dos argumentos científicos para fundamentar antigas noções de que a ambiência climática definia a ambiência social. Para Montesquieu (1772), os costumes dependiam do clima, que era o responsável pelos vícios que acabavam por fim em provocar desordem.

É o clima que deve decidir as coisas. De que serviria enclausurar as mulheres em nossos países do norte, em que seus costumes são naturalmente bons e onde todas as paixões são calmas, pouco ativas, pouco requintadas, onde o amor tem, sobre o coração, um dominio tão controlado que a menor vigilância basta para orientálas? Referindo-se à política, Montesquieu considerava que: a servidão política não depende menos da natureza do clima do que a servidão civil e doméstica (...).

O calor excessivo diminuía a força e a coragem dos homens e havia nos climas frios uma certa força de corpo e de espírito que tornava os homens capazes de ações duradouras, penosas, grandes e ousadas.

Não nos devemos, pois, espantar que a covardia dos povos de clima quente os tenha, quase sempre, tornado escravos, e que a coragem dos povos dos climas frios os tenha mantido livres. É uma conseqüência que deriva de sua causa natural Montesquieu (1772).

Foi sobre este suporte ideológico que se construiu a expansão da fronteira econômica e cultural dos países dominantes da Europa ocidental durante o período moderno. Segundo Montesquieu, na Ásia reinava um espírito de servidão historicamente incorporado à cultura daquele continente. O clima aliado à determinação da exuberância da natureza explicava para a América a inclinação de seus habitantes para a liberdade.

O que faz com que haja tantos povos selvagens na América é o fato de seu solo produzir por si próprio muitos frutos com os quais podemos nos alimentar Montesquieu (1772).

Entre os selvagens, o equilíbrio se mantinha pela preguiça; a natureza possibilitava a sobrevivência através da generosidade climática, contrariamente aos países de climas frios, onde a sobrevivência dependia de uma organização mais complexa, onde os homens deveriam trabalhar e as técnicas deveriam se desenvolver a fim de organizar indústrias capazes de garantir o bem estar das populações do norte.

Estes valores, incorporados à mentalidade européia, iriam constituir um "pano de fundo" permanente nas formulações de estudos amparados pelo desenvolvimento da biologia no século XIX. Alexandre Von Humbolt (1779-1859) tinha como objetivo científico a compreensão da totalidade complexa do universo; por isso dedicou grande parte de seu trabalho à exploração da América tropical. O principal interesse de Humbolt estava nas características físicas e biológicas, tal como demonstraram seus estudos, onde as observações efetuadas nas regiões tropicais eram destinadas a explicar as relações existentes entre vegetação, zonas de latitudes, climas e cultura, estabelecendo semelhanças entre as culturas asiáticas e nativas americanas.

A leitura e classificação dos trópicos estava basicamente fundamentada nas teorias sobre o mundo elaboradas pela História Natural. Buffon (apud Duchet, 1975) considerava em seus estudos que os homens pertenciam a uma única espécie de origem comum, contudo as raças não européias teriam sofrido um tipo de degeneração, fato que explicava o caráter primitivo dos homens dos trópicos, meros contempladores da natureza. As causas dessa especificidade do homem tropical seriam, segundo Buffon, o resultado natural da influência do clima que regulava a alimentação e os costumes. O ano de 1859 marcou a publicação do livro A Origem das Espécies de Charles Darwin, cujas idéias sobre adaptação ao meio e sobre a evolução influenciaram as ciências sociais, contribuindo para a construção científica de uma antropologia ancorada nas questões que relacionavam meio ambiente, "culturas primitivas" e civilização.

As observações da esfera biológica pareciam proporcionar a chave do entendimento científico das diferenças em níveis culturais e nas atividades econômicas, tal como explicitaram os estudos de Friedrich Ratzel (1844-1904) em sua Anthropogeographie, cujo primeiro volume apareceu em 1882.

Os olhares científicos de inúmeros viajantes que percorreram as terras do Brasil formu- 
laram minuciosos estudos sobre o exotismo da natureza e da cultura tropical, alguns bastante "imaginosos", preenchidos de pranchas e mapas deixando claro o desejo de inventariar paisagens e populações num único contexto natural. A paixão classificatória dos relatos de viagens objetivava, em grande parte, informar às academias de ciências da Europa os achados. Esta fonte de informação científica contemplava juízos que os observadores embutiam em seus estudos. No relato da viagem pelas províncias do Rio de Janeiro e Minas Gerais, Saint-Hilaire (1938) formulou em seu texto uma apreciação discreta daquilo que ele atribuía à ignorância científica do país, justificando, em parte, a necessidade das expedições estrangeiras que deveriam mostrar o Brasil ao Brasil e ao estrangeiro, apresentando como chave para o conhecimento da natureza dos trópicos o paradigma classificatório da História Natural.

Entre tantas plantas às quais se atribuem falsamente propriedades maravilhosas, algumas existem que fornecem remédios eficacíssimos. Se existisse no Brasil maior número de homens instruídos, o governo desse país faria obra de grande utilidade, nomeando para cada província uma comissão que se encarregasse de submeter a exame minucioso todas as plantas de que se utilizam os colonos para aliviar seus males. Por esse meio poder-se-ia chegar a constituir, para os vegetais, uma matéria médica brasileira, que elucidaria os colonos a respeito de remédios ineficazes ou perigosos, e ao mesmo tempo daria a conhecer aos nacionais e estrangeiros grande número de plantas benéficas Saint-Hilaire (1938).

A observação de Saint-Hilaire sobre a ignorância dos homens a respeito de sua própria região natural, sugeria que a generosidade propiciada pelo ambiente natural não significava muito, pois os benefícios da natureza só poderiam ser utilizados positivamente pela interferência do homem através da classificação que possibilitava uma seleção racional dos recursos naturais. Saint-Hilaire, em sua apreciação expressava de forma atenuada o pensamento de Buffon sobre as correspondências entre civilização, clima e natureza com as potencialidades humanas. Para Buffon (apud Duchet, 1975) a superioridade dos europeus, traduzidas na beleza e perfeição desses homens manifestavase nas relações que estes estabeleciam com a natureza, ao contrário dos homens selvagens que eram resistentes às tarefas empreendedoras, preferindo usufruir do mundo natural em seu estado bruto. A superação do estado natural, propiciada em parte pela exigências do meio ambiente menos luxurioso, possibilitava a revelação de homens superiores capazes de transformar as agruras da natureza em benefícios supremos. Assim, segundo Buffon o homem civilizado, o europeu: ...traz à luz, graças à sua arte, o que ela ocultava em seu seio. Quantos tesouros ignorados! Quantas riquezas novas! As flores, os frutos, os grãos aperfeiçoados, multiplicados até o infinito; as espécies úteis de animais transladadas, propagadas, aumentadas inumeramente, as espécies nocivas reduzidas, confinadas, relegadas; (...) as torrentes contidas, os rios dirigidos, constrangidos; (...) a terra acessivel por toda parte, por toda parte viva e fecunda; (...) os desertos trocados por cidades habitadas Duchet (1975).

Na primeira metade do século XIX, assim como os naturalistas, os médicos viajantes traçaram detalhados estudos sobre as regiões "exóticas". Os rastreadores dos trópicos incluíram nos seus registros as doenças, centrando no clima as principais questões que explicavam a natureza social, física e cultural das moléstias identificadas como causa maior dos males que abatiam a população. Martius, por exemplo, atribuiu a determinação do clima às diferenças do caráter das doenças ocorridas em São Paulo e no Rio de Janeiro.

A real inserção dos valores europeus na leitura do Brasil, efetivada pelos naturalistas, não impediu que estes elaborassem a descrição da natureza tropical como esteticamente bela e grandiosa, ao contrário dos médicos que desenharam imagens soturnas, retratos sombrios de uma natureza pestilenta, úmida e quente, propiciadora de hábitos insanos e promíscuos.

Apesar das diferenças existentes nos estilos e preocupações dos seus relatos, médicos e naturalistas fundamentaram suas conclusões sobre o paradigma que privilegiava a importância da natureza como explicação para a cultura e para o clima como determinantes da saúde das populações e do caráter dos povos.

Um outro enfoque sobre a natureza humana do Brasil, também condicionada pelo clima, reconhecia no brasileiro uma vocação nativa para o prazer, para a liberdade e para a libertinagem, características atribuídas ao comportamento coletivo, o que contribuía para o aumento do risco de propagação de doenças. Essa visão foi em parte baseada na observação dos índios, tidos como indolentes, pouco ades- 
trados para o trabalho regular, adeptos das danças e das bebidas fermentadas, traiçoeiros, desconfiados e rebeldes. Quase animais, preferiam a morte ao cativeiro. A intensa proximidade entre brancos, negros e índios, favorecia a expansão de uma mestiçagem degenerada, refrataria à ordem requerida pelas sociedades civilizadas.

Assim, o clima foi também um argumento relevante para explicar a triste realidade da miscigenação, pois o calor favorecia a exibição dos corpos semi despidos, suados; cenas do quotidiano que estimulavam uma sensualidade não controlada, hábitos que possibilitavam, em parte, o contágio e a propagação de doenças. Em seu livro, publicado em 1848, Études sur le Brésil, o médico francês, Dr. Alphonse Rendu, quando do relato que descreve os brasileiros, concluía que les jeunes Brésiliens sont souvent pervertis presque au sortir de l'enfanse; outre l'exemple de leurs pères qu'ils ont sous les yeux, garçons et filles, maîtres et esclaves, passent ensemble la plus grande partie de la journée à demi vêtus; la chaleur du climat hâte le moment de la puberté, les désirs excités par une éducation vicieuse el le mélange des sexes sont souvent provoqués par les négresses, et ne rencontrent jamais d'obstacles; la débauche s'empare peu à peu de ces enfants et les précipite bientôt dans un abattement physique et moral Rendu (1848).

O julgamento feito por Rendu, fazia parte do imaginário europeu sobre um mundo desconhecido, misterioso e primitivo, onde os homens agiam segundo o clamor da natureza; por isso expressavam livremente seus desejos e eram mais afeitos aos prazeres furtivos. A própria composição física dos habitantes dos trópicos favorecia uma maior agilidade e sensualidade dos gestos e da expressão corporal, o que facilitava o alcance do prazer exigido somente pelo corpo destituído de sentimento e espiritualidade, sendo o ato sexual quase uma manifestação do instinto.

Montesquieu (1772), descreveu para a Enciclopédia (1762) um verbete onde os habitantes das regiões de clima quente eram apresentados aos europeus como (...) menores, mais magros, mais vivos, mais alegres, comumente espirituosos, menos laboriosos, menos vigorosos (...) que os habitantes dos paises frios; (...) que nos climas muito quentes, o amor é nos dois sexos um desejo cego e impetuoso, uma função corporal, um apetite, um grito da natureza, (...) que nos climas temperados ele é uma paixão da al- ma, uma afeição refletida, meditada, analisada, sistemática, um produto da educação Montesquieu (1772).

O desdobramento de tais formulações, desaguariam nas teses que associaram clima e inferioridade cultural, fatores decisivos para explicar a miscigenação, fato que justificava a idéia da inferioridade racial. Para muitos autores, a mestiçagem favoreceu a moldagem de uma sub-raça indolente, incapaz para o trabalho construtivo e reprodutor. Gobineau (apud Peixoto, 1975), por exemplo, baseado nesta idéia profetizou a extinção do Brasil.

O setenciamento dos "tristes trópicos", expressão usada por Claude Levi-Strauss, foi comum nos registros científicos. Citamos como exemplo os de Bryce apud Peixoto (1975) e Buckle apud Peixoto (1975). O primeiro, após observar a flora brasileira, verificando um grande número de espécies vegetais em pequenos espaços e comparando-a com a vegetação gregária da Europa, colocou a seguinte questão. Se a flora apresentava tal desagregação, os animais, os homens não seriam também desagregados?

Buckle apud Peixoto (1975), considerando mais o aspecto climático, afirmou que o excesso de calor e de umidade dificultava no Brasil a constituição de uma civilização avançada, buscando como prova de sua afirmação, a comparação entre os "selvagens" brasileiros, os incas e os astecas Peixoto (1975).

Esta visão fatalista dos habitantes dos trópicos pode ser identificada ainda hoje. O homem nordestino, o sertanejo em particular, o "paraíba", é tido nos centros urbanos, sobretudo nos do Sudeste, como ser inferiorizado, no largo contexto de vida da espécie a que pertence. Homem - quase se pode dizer - mutante, não genético, propriamente, mas ambiental, das características originais de seus semelhantes. Inferioridade que se exterioriza no nanismo físico e no retardo mental, mas atestada pela desnutrição, pelas parasitoses e infecções, sempre presentes como razões causais da injúria orgânica. Gente de obituário precoce e de saúde constantemente abalada Pereira (1990).

De uma certa forma, o sertanejo nordestino é a versão atualizada do "Jeca Tatu”, personagem de Monteiro Lobato, metáfora de um Brasil miserável, improdutivo, ignorante, doente, responsável também pela desgraça política do país. Para "Jeca Tatu", o ato mais importante da sua vida é votar no governo. Vota. Não sabe em quem, mas vota Barbosa, (1981). 
Abrimos aqui um parêntese para lembrar que uma das grandes polêmicas sobre miscigenação e propagação de doenças, pautou-se sobre o tema da "sifilização do Brasil". Segundo Gilberto Freyre (1993), a sifilização começou a ocorrer quando dos primeiros encontros fortuitos de europeus com índias nas praias da costa brasileira. A grande epidemia da doença na França no século XVI, teria sido a principal causa da transferência da doença para o Brasil. Contudo os mesmos estudos mostram que estavam também os portugueses infectados, pois o mal assolou o Velho Mundo em fins do século XV Freyre (1993).

Alguns estrangeiros, como Sigaud, atribuíram à sífilis um caráter tropical, contudo os primeiros viajantes e cronistas que se referem ao clima e às doenças do Brasil não assinalaram a existência da doença entre os índios que viviam isolados e mantinham-se longe do contato com os europeus.

A incidência de doenças estaria também ligada à perversão moral, à bestialidade e ao sadismo, comportamentos moldados nos homens brasileiros desde da infância, pois a proximidade com os animais domésticos e com os negros escravos favorecia o despertar de uma sexualidade anormal induzida pelos efeitos do clima sobre os hábitos e desejos humanos.

No que diz respeito à ação médica, a redução dos efeitos maléficos do clima sobre a saúde dos homens centrava-se na perspectiva de fundamentar a identificação da doença e sua classificação através dos sinais externos e de sua relação direta com os elementos do meio ambiente, com a alimentação e com os costumes. Os ares das regiões quentes não eram salubres e um dos fatores agravantes dessa má qualidade do meio ambiente era a existência de inúmeros sítios pantanosos determinado pela umidade. A razão teórica da medicina para explicar a inferioridade climática dos trópicos era comprovada pela insalubridade dessas regiões, confirmada em estudos científicos que verificaram que nos pântanos estão em digestão e dissolução substâncias animais e vegetais, as quais na presença de grandes calores, entrando em putrefação, dão origem a pestíferos gases, que devem levar a todos os viventes os preliminares da morte, já pela sua ação imediata na periferia do corpo, e continuação das suas membranas, já pela entrada nos órgãos da respiração Silva (1808).

Em torno dessa razão teórica da medicina miasmática, as medidas práticas aconselha- vam o controle das doenças através da drenagem dos pântanos para os aterros, e o saneamento e a urbanização das cidades, formulando um ideal higiênico, que visava ao estabelecimento de normas profiláticas prescritas para os corpos e para as relações sociais.

A orientação indicada pelo higienismo revelava a possibilidade de neutralizar os efeitos negativos do clima em benefício da construção de uma sociedade organizada e civilizada.

O grande projeto de recuperação da imagem do Brasil, país tido como pestilento e devorador de estrangeiros, foi arquitetado e executado como meta prioritária do governo de Rodrigues Alves, que prometia a modernização visível dos centros urbanos a curto prazo. Para realizar a recuperação sanitária do Rio de Janeiro, o governo convocou o médico Oswaldo Cruz, que utilizando-se dos métodos recomendados pela bacteriologia, alcançou um inquestionável sucesso no combate às epidemias que graçavam na cidade. Estava a bacteriologia no centro do foco científico, imprimindo e modificando conceitos nas ciências da saúde, determinando a natureza microbiana das doenças e indicando terapêuticas baseadas neste princípio.

Como sabemos, a bacteriologia permitiu aos países dominantes da Europa a ocupação dos territórios coloniais da África e da Ásia, onde as doenças "tropicais" representavam um efetivo risco para os colonizadores. Os países mais envolvidos na partilha da África durante o século XIX, criaram seus institutos de medicina tropical. Os mais importantes foram, o Instituto de Medicina Tropical de Hamburgo, o Curso de Medicina Colonial de Paris, a London School of Tropical Medicine, a Liverpool School of Tropical Medicine, o Tropical Iara da Holanda, a Écule de Medicina Tropical da Bélgica, além do Instituto Pasteur de Paris, um dos principais irradiadores do saber elaborado pela microbiologia.

\section{A reconstrução do conceito de "doença tropical" e a autoridade científica de Carlos Chagas. A valorização da ciência}

No fim do século XIX, franceses, ingleses e alemães, deixaram o confortável e organizado solo europeu para habitar e dominar um mundo de hábitos, cores, clima e doenças exóticos. Nesse mundo agressivo e inóspito, o inimigo principal era invisível, o microrganismo que 
fazia de sua aparente passividade a principal resistência à penetração de corpos estrangeiros no macromundo político econômico, social e cultural.

Armados com o saber da microbiologia, os "missionários" da nova ciência elaboraram pesquisas para tornar visível os agentes patogênicos das doenças tropicais que poderiam comprometer a ocupação européia. Segundo Albert Delaunay (1962) Os brancos não suportam climas desconhecidos para eles; sobretudo porque sofrem com as doenças infeciosas, perdas terríveis. Tem-se a sensação de que toda uma patologia específica deve ser criada para que se possa estabelecer, em seguida, uma profilaxia. A bacteriologia, única capaz de resolver dificuldades, se torna então o centro de todas as atenções” (Delaunay, 1962).

Grande parte dos tratados médicos baseados na teoria microbiana sobre "doenças exóticas", associaram os aspectos climáticos dos países de clima quente com as patologias infecciosas e parasitárias. Estes tratados atribuíram à ciência microbiológica o poder e a real possibilidade de controlar um universo mais amplo, interferindo na organização social, imprimindo políticas, reorganizando a economia e reavaliando valores culturais.

No Précis de Pathologie Exotique de Jeanselme e Rist (1909), o discurso político colonialista justifica a urgência das pesquisas científicas sobre as doenças parasitáriasl $\mathrm{O}$ discurso médico deixa de ter uma conotação do observador externo, para ser o formulador de ações precisas sobre os perigos oferecidos pelos trópicos, não só para o colono, mas sobretudo, ao projeto colonial. O perigo tropical é visualizado nas endemias que comprometem a energia e a saúde da força de trabalho.

A velha Europa continua conscientemente na conquista de terras inexploradas, para lá vende seus produtos (...), mas o branco não pode se manter neste meio hostil, senão na condição expressa de se conformar estritamente com as regras da higiene e da profilaxia(...). As grandes endemias tropicais fazem também vítimas entre as raças de cor, onde não há colonização possível, na zona tórrida, sem a ajuda da mão-de-obra nativa. Dela, na maior parte, depende o sucesso. Ela é o braço que deve executar obedientemete, o que o cérebro do branco concebeu(...). O conhecimento das doenças dos países quentes aparece portanto como uma necessidade pública. (Jeanselme \& Rist, 1909).
As novas perspectivas científicas das pesquisas praticadas pelos europeus nos trópicos, sobretudo as realizadas pelos pastorianos nas colônias francesas da África e da Ásia, atribuíram grande importância ao clima para a definição de patologias, confirmando o termo tropical. Dessa forma, a nosologia relacionada com o clima foi um dos elementos teóricos que definiu o modelo de investigação da parasitologia fundamentada na microbiologia e, em última análise, estabeleceu como "verdades científicas” as diretrizes teóricas e metodológicas inscritas no modelo experimental.

Para Carlos Chagas (1903) o período da ciência inaugurado por Pasteur representou a "renascença da medicina" através da "via segura da experimentação", meio pelo qual se abandonaram as "hipóteses arbitrárias" para o rigor da observação clínica, estabelecendo o determinismo dos fenômenos mórbidos. Para tanto, dava-se base anatômica às concepções patogênicas, estabelecendo, finalmente pela obra genial de Pasteur, a etiologia da moléstia.

A medicina experimental baseada na microbiologia era tida como a "chave" com a qual se abririam as possibilidades de resolução de todas as questões ligadas ao entendimento do universo vivo, percebendo-o em suas multiplicidades cíclicas de reprodução da vida em todas as suas dimensões. A via da experimentação microbiológica permitia o entrecruzamento de vários domínios do conhecimento científico capazes de respaldar a eficiência do modelo e formular, para o cientista, uma concepção otimista frente ao universo microscópico, agora visível e dizível. Esta certeza nas possibilidades da experimentação era traduzida por Chagas como uma profunda confiança na "vitória" da ciência no combate às entidades mórbidas. A doença vista enquanto moléstia tinha agora uma designação de caráter provisório e caberia à microbiologia fornecer os elementos da "cura infalível" ou as soluções profiláticas das entidades mórbidas dos maiores flagelos humanos através dos soros curativos e pelas vacinas imunizantes.

Como observamos, Carlos Chagas atribuía à microbiologia a certeza de solução para todas as questões apresentadas como desafio ao domínio de conhecimento das ciências da saúde. Imbuído dessa convicção, Chagas dirigiu seu interesse para as investigações das doenças parasitárias, primeiro a malária e depois a tripanossomíase americana, entidade mórbida por ele definida como patologia específica, 
em 1909, e conseqüentemente classificada como doença tropical. A partir desse momento, Chagas iria levantar um grande debate para reavaliação e relativização do conceito de doença tropical, definida também como, doenças dos países quentes ou doenças exóticas, defendendo a necessidade da criação de uma área de conhecimento própria para o estudo de doenças tropicais na Faculdade de Medicina do Rio de Janeiro. Seu discurso tinha duas direções, uma no sentido político institucional, outra no sentido estritamente científico.

A justificativa política, buscava o modelo europeu para reforçar seus argumentos para oficializar uma cadeira de doenças tropicais.

As nações da Europa, zelosas de suas colônias nos trópicos, organizaram-se em especializações, seja nas universidades ou em grandes institutos de pesquisas, o estudo e o ensino da patologia dos países quentes. Aqui, não tanto os interesses de ordem econômica, quanto deveres do mais exaltado e previdente nacionalismo nos obrigam ao estudo e à pesquisa da nosologia brasileira, a fim de promover o aperfeiçoamento de nossa raça, de raros predicados nativos, e realizar, pelo método profilático, a redenção sanitária de nosso território Chagas (1926a).

Chagas pronunciava um discurso de autoridade científica, reconhecida internacionalmente graças ao impacto de sua descoberta. Foi respaldado, em parte, neste poder que Chagas assumiu a sucessão de Oswaldo Cruz na direção do Instituto Oswaldo Cruz, posição que favoreceu a introdução no espaço institucional da Faculdade de Medicina, o saber biomédico produzido em Manguinhos.

O discurso científico relativizava o conceito de doença tropical; assim Chagas iria distinguir o aspecto climático do geográfico: $o$ clima afeiçoa a nosologia dos países quentes.

Com esta afirmação, Chagas iria recuperar o debate conceitual das denominadas patologias tropicais. Pelo fato de estarem situados os países do hemisfério sul na faixa climática de predominância tropical, eles não estavam condenados à exclusividade das patologias parasitárias (as mais identificadas como tropicais), assim como os países do hemisfério norte, de clima temperado, não estavam a salvo das mesmas. Dessa maneira, a denominação tropical ou exótica, era um artifício classificatório, que sintetizava, para além das doenças e do clima, um valor cultural incorporado historicamente na mentalidade européia. Segundo Chagas são muito poucas, em verdade, e con- tam-se por algumas unidades apenas, as doenças exclusivas dos países tropicais, e também, raríssimas aquelas circunscritas aos países frios e temperados. A maioria das espécies mórbidas escapam as delimitações geográficas, nas quais se deveria basear o conceito de uma patologia de latitudes, e as mesmas doenças se representam nos quadros nosológicos de todas as regiões do globo. A sifilis, a tuberculose, o câncer, as infecções do grupo colli-tifo, as pneumopatias infecciosas, as parasitoses intestinais, e grande número de outras espécies infecciosas, atingem o homem em quaisquer zonas da terra, desde as mais frias, de climas glaciais, até as de temperaturas mais elevadas, de climas tórridos. E se assim 'e relativamente' as infecções, mais se afirma a uniformidade nosológica, em todos os países, quando apreciamos os processos mórbidos que independem, mediata ou imediatamente, de agentes animados. Na patologia de aparelhos e sistemas orgânicos nunca se decifram variantes regionais apreciáveis, senão constância dos elementos fundamentais e dos sinais, que por toda parte se caracterizam. Por outro lado, mesmo no agrupamento das entidades mórbidas, que o critério epidemiológico unânime reuniu e classificou, mesmo aí, a maioria das doenças transpõe os limites geográficos das zonas equatoriais que se verifica em países de clima temperado ou mesmo frio Chagas (1926a).

Como exemplo da problemática da classificação das patologias ditas exóticas, o paludismo, moléstia mais vulgarizada como "perigo dos trópicos", tinha focos tradicionais na Europa, como na Itália e nas regiões mineiras da Europa Setentrional. Sendo doença caracterizada como cosmopolita, era verificada sob a forma endemo-epidêmica, mesmo nos países de clima frio e temperado. Contudo, a Amazônia, por exemplo, oferecia, segundo Chagas, as condições climatológicas ótimas para à evolução sexual do protozoário, a sua propagação e o estímulo à voracidade sugadora do mosquito transmissor.

Também as duas tripanossomíases humanas, a doença de Chagas e a doença do sono, constituíam nos níveis epidemiológicos e endêmicos, patologias características dos climas tropicais e subtropicais. O próprio descobridor da tripanossomíase americana deixava claro em seu estudos que sabemos que estas doenças não são exclusivas de países quentes, porque uma e outra têm sido verificadas em zonas frias ou temperadas, onde existem apenas os agentes transmissores; mas, como as influências clima- 
tológicas se exercitam intensas sobre as glossinas e sobre os triatomas, e se fazem ainda sentir sobre a biologia dos flagelados, modificandolhes as condições de evolução no hematófago, a epidemiologia e a curva endemo-epidêmica dessas doenças apresentam feição correlata (Chagas, 1926a).

A peste bubônica e o cólera foram flagelos europeus, não só nas regiões portuárias do Mediterrâneo, mas também na Rússia, apesar das baixas temperaturas.

O calazar fez parte do quadro epidemiológico da Espanha e foi registrado em outros países da Europa. A difusão da leishmaniose cutânea na Argentina contribuiu para reforçar o argumento de que as doenças, ditas tropicais, escapavam às restrições climáticas que fundamentavam a classificação e a nomenclatura adotada.

A lógica que orientou esta classificação estava baseada nas características específicas das manifestações mórbidas das doenças, modificadas pelas condiçõos climáticas, o que determinava uma observação biológica diferenciada dos agentes patogênicos nas regiões tropicais. Utilizando-se desses pressupostos, Carlos Chagas justificou o estabelecimento de um ensino próprio no domínio da medicina tropical no Brasil, explicitando que não faltam à patologia dos países quentes características fundamentais, que a delimitam como ramo especial da medicina" Chagas (1926a).

Estas características estavam portanto, no âmbito das "verdades científicas", ligadas às "exigências biológicas" dos germes patogênicos e no mecanismo de sua difusão nos climas quentes, pois a compreensão da doença dependia da elucidação de três aspectos, ou seja, o contágio, o meio e a virulência.

Para a teoria microbiana, no contágio direto, o meio era irrelevante, pois os germes não encontrando o meio exterior favorável não eram capazes de processar organicamente a evolução, a transformação, para permanecer. $\mathrm{O}$ contágio direto dava-se de indivíduo a indivíduo.

Para o contágio indireto, o clima, entendido como meio externo, assumia importância fundamental, pois determinava a vitalidade do germe e propiciava o contágio permanente através das condições mesológicas ideais, permitindo uma relação vital perfeita entre o agente patogênico e seu hospedeiro.

A partir das diferenças estabelecidas entre contágio direto e indireto, as patologias exó- ticas ou tropicais, inscreveram-se na ciência dos vetores, visto que o meio, sobretudo o fator climático, fundamentava a teoria da veiculação mecânica dos agentes patogênicos.

No final do século XIX e início do XX, as investigações realizadas pelos cientistas dos grandes centros de pesquisas europeus nas colônias da Ásia e da África, resultaram em descobertas significativas no campo da parasitologia orientada pelo modelo microbioano. Bruno Latour refere-se à três possibilidades que explicam o sucesso do novo modelo científico na intervenção sobre as doenças "exóticas" nos territórios coloniais da Europa, da África e da Ásia.

Primeiro, a maior parte das doenças eram novas. A clínica era unicamente feita pelos médicos militares, os primeiros a usarem a pasteurização. Os pastorianos não precisavam pois de usar velhas clinicas seculares. Segundo, as doenças que poderiam despertar interesse, eram todas provocadas por germes ou por parasitas. Terceiro, a maior parte das doenças acompanhava o ciclo de vida dos insetos Latour (1984).

Ao abordar a pertinência entre vetores e climas para fundamentar cientificamente a denominação "nosologia dos países quentes", Chagas afirmaria que bastará de sobra para concretizar o raciocínio emitido, referir apenas alguns aspectos da nosologia dos países quentes; e melhor e o mais depressa podemos concluir, se argumentarmos com as doenças transmitidas pelos insetos sugadores, nos quais é decisiva a influência dos fatores climáticos, que aí se exercitam principalmente, senão exclusivamente, sobre a biologia do germe patogênico e do agente transmissor Chagas (1926).

A microbiologia, como vimos, forneceu os elementos teóricos e metodológicos para reavaliar e relativizar o conceito de "doença tropical” para enfim legitimá-lo e confirmá-lo.

Reconhece-se hoje a medicina tropical, como domínio da ciência voltada para as infeções e parasitoses, que são as causas mais comuns do comprometimento da saúde humana na zona intertropical do globo. Esta especialidade têm sido ampliada em função da identificação de uma diversificada natureza dessas afeções nos trópicos.

A visão fatalista dos trópicos, cujo principal componente foi a determinação climática, está hoje minimizada pela noção de que as doenças são sociais, economicamente impostas e ecologicamente ambientadas. As inter- 
pretações que priorizaram os aspectos físicos e naturais na determinação das doenças, tenderam a colocar sob um mesmo plano natural-a-histórico os elementos climáticos, geo-

\section{Referências}

Barbosa R 1981. A questão social e política no Brasil. Ciência e Trópico 9(2): 171-175.

Chagas C 1903. Estudos Hematológicos no Impaludismo. Tese Inaugural. Instituto de Manguinhos, Rio de Janeiro.

Chagas C 1926a. Aula Inaugural do Professor Carlos Chagas no Pavilhão Miguel Couto, Faculdade de Medicina do Rio de Janeiro, Rio de Janeiro.

Chagas C 1926b. As Doenças Tropicais. Jornal do Commércio, Rio de Janeiro.

Delaunay A 1962. L'Institut Pasteur; des Origines à Aujourd'hui. Editions France-Empire, Paris.

Duchet M 1975. Antropologia e Historia en el Siglo de las Luces-Buffon, Rousseau, Voltaire, Helvecio, Diderot. Siglo Ventiuno, México.

Enciclopédia 1762. Encyclopédie ou Dictionnaire Raisonné des Sciences, des Arts et Métiers. Briasson, Paris.

Freyre G 1993. Casa Grande \& Senzala. Círculo do Livro, São Paulo. gráficos, biológicos, etc., reduzindo o homem à sua dimensão animal e convertendo a produção da cultura e da sociedade num elemento a mais do meio.
Jeanselme E, Rist E 1909. Précis de Pathologie Exotique. Masson et Cie éditeurs, Paris.

Latour B 1984. Les Microbes, Guerre et Paix: Suivi des Irréductions. A.M. Métaillé, Paris.

Montesquieu 1772. Do Espírito das Leis. São Paulo, 1962.

Peixoto A 1975. Clima e Saúde. Companhia Editora Nacional, São Paulo.

Pereira G 1990. Nordeste de Gilberto Freyre. Ecologia e doença em Pernambuco. Ciência e Trópico 18(2): 164-217.

Rendu A 1848. Études sur le Brésil. Chez J-B Baillière, Paris.

Saint-Hilaire A 1938. Viagem pelas Províncias do Rio de Janeiro e Minas Gerais. Nacional, São Paulo.

Silva MV 1808. Reflexões sobre Alguns dos Meios Propostos, por Mais Conducentes, para Melhorar o Clima da Cidade do Rio de Janeiro. Impressão Regia, Rio de Janeiro. 